Published in: The Journal of Contemporary Dental Practice, Volume 9, No. 6 , September 1, 2008

\title{
Histologic Study of the Effect of Laser Therapy on Bone Repair
}

Blaya DS, Guimarães MB, Pozza DH, Weber JB, de Oliveira MG.

Centro Universitário Franciscano, Santa Maria, RS, Brazil.

\begin{abstract}
Aim: This study used histologic analysis and HE staining to evaluate laser biomodulation of bone repair in cavities made in the femurs of rats that underwent non-ablative laser irradiation.

Methods and Materials: Eighteen male Wistar rats weighing 300 to 400 grams were randomly assigned to three groups of six animals each. A surgical defect site was produced with a trephine about $2 \mathrm{~mm}$ in diameter under abundant irrigation. In Group I the complete surgical protocol to produce a bone defect was followed but without laser radiation (control). In Group II a continuous wave $830 \mathrm{~nm}$ infrared laser was used at $10 \mathrm{~J} / \mathrm{cm} 2$ and $50 \mathrm{~mW}$ at each point of the surgical site. In Group III a continuous wave $685 \mathrm{~nm}$ infrared laser at $10 \mathrm{~J} / \mathrm{cm} 2$ and $35 \mathrm{~mW}$ was used at each point of surgical site. The animals were irradiated at intervals of 48 hours beginning immediately after the preparation of the defect and were sacrificed on the 15th, 21st, and 30th days. Slides were studied by means of descriptive analysis.
\end{abstract}

Results: Greater degrees of new bone formation and vertical regeneration were found in the irradiated groups than in the control group.

Conclusion: Laser therapy in this study protocol was efficient in promoting bone repair.

Clinical Significance: The use of laser technology has been used to improve the clinical results of bone surgeries and to promote a more comfortable postoperative period and quicker healing.

Keywords: Wistar rats, lasers, bone healing, bone histology

\section{Introduction}

For a long time laser biomodulating activity was called biostimulation because this was the first biomodulating effect to be described. Currently biomodulation can be achieved by using smaller and more practical laser units which can be operated at low power settings (1 to $500 \mathrm{~mW}$ ). These units have been described in several forms in the literature such as a low-level laser, soft laser, or therapeutic laser.1,2 Although laser phototherapy to accelerate wound repair was introduced in 1972 by Mester et al.3 its use remains poorly defined and is still rejected in several countries. 4

Laser therapy has used large spectrums of visible and infrared light. The first studies focused on visible light helium-neon ( $\mathrm{He}-\mathrm{Ne}$ ), argonium, or kriptonium lasers. Semiconductor gallium arsenide (GaAs) and gallium-aluminum-arsenide 
(GaAlAs) diode lasers have become available more recently and have been intensively used and studied.5,6

Tissue healing is a complex process that involves local and systemic organic activity, and fibroblasts are some of the cells directly involved in this mechanism. The action of lasers in healing is also widely therapeutic by inducing local and systemic regenerative, anti-inflammatory, and analgesic effects. These effects have been demonstrated in vitro and in vivo, particularly in studies that focus on the increase of local microcirculation, activation of the lymphatic system, proliferation of epithelial cells and fibroblasts, and increased collagen synthesis by fibroblasts.7,8 Pinheiro et al.8 has suggested, although the benefits of laser in soft tissue healing have been demonstrated, the effects of nonablative laser on bone are still controversial, and study results are conflicting.

Several in vivo and in vitro studies have investigated the use of laser therapy in the biomodulation of bone repair through its photochemical and photobiologic properties. Their aim is to provide patients with a more comfortable postoperative recovery and faster healing. $9-12$

This study used histologic analysis and HE staining to evaluate the biomodulation of bone repair in cavities in the femurs of rats that underwent nonablative laser irradiation.

\section{Methods and Materials}

This study was approved by the Committee on Science and Ethics of the School of Dentistry, Pontifícia Universidade Católica do Rio Grande do Sul, Porto Alegre, Brazil.

Eighteen male Wistar rats, weighing 300 to 400 grams, were randomly selected and distributed into three groups of six animals each.

The surgical defect site was standardized by implanting a $3 \mathrm{~mm}$ long microscrew in the lateral proximal region of the femur. From it, $5 \mathrm{~mm}$ were measured for the location of the bone cavity, which was produced with a trephine about $2 \mathrm{~mm}$ in diameter under abundant irrigation.

In all groups results were analyzed at 15,21 , and 30 days after surgical procedures. Therefore, each group was further divided into three subgroups ( $A$, $\mathrm{B}$, and $\mathrm{C}$ ) according to each time point (Table 1).

Table 1. Distribution of groups and subgroups according to time points and analysis criteria.

\begin{tabular}{|c|c|c|c|c|}
\hline Group & Procedures & Subgroups & Time point & Analysis criteria \\
\hline \multirow{3}{*}{ I } & \multirow{3}{*}{ Control } & I-A & 15 days & Histological \\
\hline & & I-B & 21 days & Histological \\
\hline & & I-C & 30 days & Histological \\
\hline \multirow{3}{*}{ II } & \multirow{3}{*}{$\lambda-830-\mathrm{nm}$ laser } & II-A & 15 days & Histological \\
\hline & & II-B & 21 days & Histological \\
\hline & & $\|-C$ & 30 days & Histological \\
\hline \multirow{3}{*}{ III } & \multirow{3}{*}{$\lambda-685-n m$ laser } & III-A & 15 days & Histological \\
\hline & & III-B & 21 days & Histological \\
\hline & & $\|I\|-C$ & 30 days & Histological \\
\hline
\end{tabular}


In Group II an infrared diode laser unit (GaAIAs; THERA LASE $®$, DMC Equipamentos, São Carlos, Brazil) was used at a $830 \mathrm{~nm}$ continuous wave irradiation. The irradiation dose was $10 \mathrm{~J} / \mathrm{cm} 2$ applied continuously to one point in the surgical site at $50 \mathrm{~mW}$ immediately after the end of surgery and at each 48 hours which totaled eight applications on the 15th day. In Group III animals were irradiated with $\lambda-685 \mathrm{~nm}$ continuous wave indium-gallium-aluminumphosphide red laser (InGaAIP; THERA LASE®) applied to one point.

The dose was also $10 \mathrm{~J} / \mathrm{cm} 2$ applied at $35 \mathrm{~mW}$. In Group I (control) the animals underwent the same procedure as the animals in the other groups but the laser unit was not turned on.10 The animals were sacrificed 15, 21, and 30 days after surgery. Specimens were harvested and macroscopically assessed, then stored in $10 \%$ formalin for 24 hours. The specimens were then processed in the routine manner (wax and stain with $\mathrm{H} \& \mathrm{E}$ ) and analyzed under light microscopy (ZeissAxiolad $\AA$, Carl Zeiss Vision, Hallbergmoos, Germany) at 40x magnification. The following parameters were used for analyses: degree of vertical regeneration, new bone formation, and corticalization.

\section{Results}

This study compared the degree of vertical regeneration, new bone formation, and corticalization with and without laser radiation (LLLT) following a standardized surgical protocol. Up to day 21 following surgery the presence of new bone formation in surgical defects was more advanced in Groups II and III (Figures 1 and 2, respectively) than in the control group. In the control group (Group 1) similar new bone formation was observed on the 30th day (Figure 3). There was a significant difference in the degree of vertical regeneration (Table 2 ) and in the degree of new bone formation (Table 3) between study groups to which values were assigned to the different degrees of new bone formation. The Kruskal-Wallis test was used for statistical analysis. In this analysis the control group had lower values of vertical regeneration and new bone formation than the infrared and red laser groups, which did not differ from each other $(p \leq$ 0.01 ). Corticalization was not significantly different between groups when the analysis consisted of only two variables; the presence or absence of corticalization. The chi-square test was used for statistical analysis $(p=0.09)$.

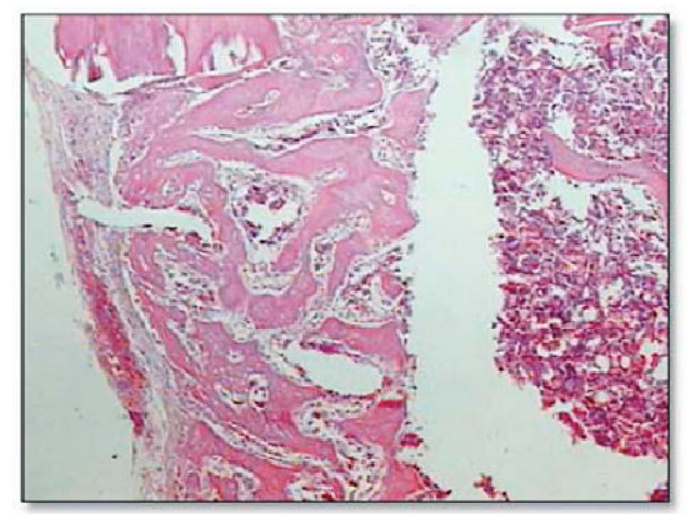

Figure 1. Photomicrography of group II-B (infra-red laser - 21 days). Presence of neoformed trabeculae bone in surgical defect (HE). 


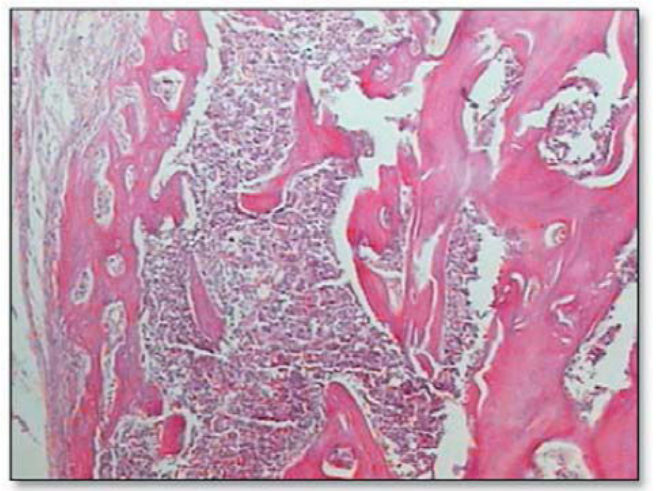

Figure 2. Photomicrography of group III-B (Red laser - 21 days). Presence of neoformed trabeculae bone in surgical defect $(\mathrm{HE})$.

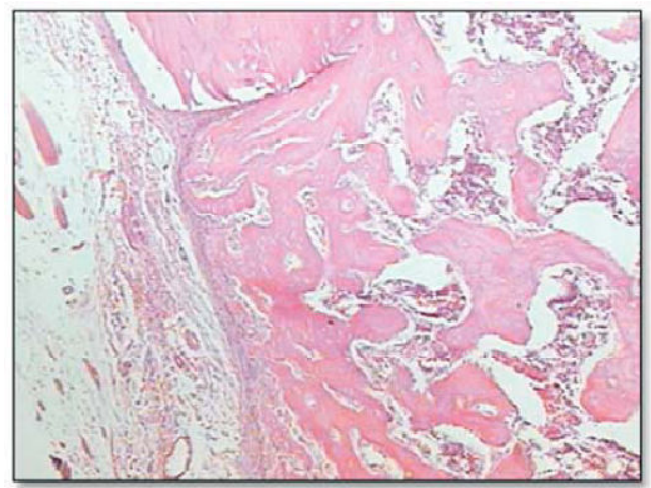

Figure 3. Photomicrography of group I-C (Control group - 30 days). Presence of neoformed trabeculae bone in surgical defect (HE).

Table 2. Comparison of vertical regeneration between the groups according to time points.

\begin{tabular}{|l|c|c|c|c|}
\hline \multirow{2}{*}{ Vertical regeneration } & \multicolumn{3}{c|}{ Group } & \multirow{2}{*}{ Total } \\
\cline { 2 - 4 } & Control & Infrared laser & Red laser & \\
\hline Absent & - & - & - & - \\
\hline Partial & $3(50 \%)$ & - & - & $3(16.7 \%)$ \\
\hline Total (degrees < diaphysis) & $3(50 \%)$ & - & $3(50 \%)$ & $6(33.3 \%)$ \\
\hline Total (" diaphysis) & - & $6(100 \%)$ & $3(50 \%)$ & $9(50 \%)$ \\
\hline Total & $6(100 \%)$ & $6(100 \%)$ & $6(100 \%)$ & $18(100 \%)$ \\
\hline Source: resoarch data (PuCRS. Poto Alegre, Braz) & & & & \\
\hline
\end{tabular}

Table 3. Comparison of bone formation between the groups according to time points.

\begin{tabular}{|l|c|c|c|c|}
\hline \multirow{2}{*}{ Bone formation } & \multicolumn{3}{|c|}{ Group } & \multirow{2}{*}{ Total } \\
\cline { 2 - 4 } & Control & Infrared laser & Control & \\
\hline Absent & - & - & - & - \\
\hline Moderate & $4(66.7 \%)$ & - & - & $4(22.2 \%)$ \\
\hline High & $2(33.3 \%)$ & $2(33.3 \%)$ & $4(66.7 \%)$ & $8(44.4 \%)$ \\
\hline Intense & - & $4(66.7 \%)$ & $2(33.3 \%)$ & $6(33.3 \%)$ \\
\hline Tulal & $6(100 \%)$ & $6(100 \%)$ & $6(100 \%)$ & $18(100 \%)$ \\
\hline Sourco: research data (PUCRS. Porto Alogro, Brazi). & & & \\
\hline
\end{tabular}

\section{Discussion}

Tissue biomodulation is one of the most controversial uses for lasers in dentistry. 1 While most uses of laser therapy in dentistry are applied to soft tissues, there is a growing interest in the use of nonablative lasers for tooth structure and bone.2 However, bone healing differs substantially from soft tissue healing because of its morphology and composition. Generally bone healing processes are slower than those of soft tissues. The natural course of 
bone healing follows consecutive phases that differ from each other according to the type and intensity of trauma and the extent of bone damage.8 All study groups showed some degree of new bone formation and cortical bridging. The irradiated groups had a greater degree of corticalization and new bone formation after the 15th day. None of the groups showed pathologic bone resorption or ingrowth of connective tissue into the cavity which confirms the biostimulatory effect of laser therapy. The use of other slide staining techniques to evaluate collagen and the organization of collagen fibers so the efficacy of laser therapy can be further confirmed is suggested.

A review of literature shows in vivo studies vary greatly in terms of type of laser, dose, and irradiation methods used which complicates comparisons between them. $7,9,11,13,14$ All study groups showed greater bone remodeling activity at the first study time point (15 days) and a trend to stabilization from the 21st to the $31^{\text {st }}$ day, which may confirm the stimulation of cell proliferation by both red and infrared lasers in the initial stages of healing.10,12,15 In sum, the results of this study showed laser therapy facilitated bone repair. Irradiation with infrared and red laser accelerated the primary regenerative process, improved the quality of bone structure, and produced a more compact bone than in the control group.

The present findings may have clinical applications in the placement of immediate implants which are protected from direct occlusal forces but may be subject to trauma during mastication. For example, if bone remodeling is stimulated using laser therapy, better osseointegration and surgery results may be achieved.

Laser therapy may also have other direct applications in clinical dentistry, such as in the treatment of mandibular fractures or in osteotomy cases. In such situations the rate of bone repair may be accelerated and the time required for intermaxillary fixation may be shortened. Future studies are needed to confirm these possibilities.

\section{Conclusion}

This study showed eight red or infrared laser applications (10 J/cm2) significantly increased bone formation and the degree of vertical bone regeneration. It did not affect the degree of cortical bone formation in the animal model studied.

\section{Clinical Significance}

The use of laser technology has been used to improve the clinical results of bone surgeries and to promote a more rapid, comfortable postoperative healing period.

\section{References}

1. Pinheiro ALB, Frame JW. Laser em odontologia: seu uso atual e perspectives futuras. Rev Gaucha Odontol. 1992; 40(5):327-32.

2. Walsh LJ. The current status of low level laser therapy in dentistry. Part 1. Soft tissue applications. Aust Dent J. 1997; 42:247-54.

3. Mester E, Spiry F, Szende B, Tota JG. Effect of laser rays on wound healing. Am J Surg. 1971; 122:532-5.

4. David R, Nissan M, Cohen I, Soudry M. Effect of low-power He-Ne laser on fracture healing in rats. Lasers Surg Med. 1996; 19(4):458-64. 
5. Basford JR. Low-energy laser treatment of pain and wounds: hype, hope, or hokum? Mayo Clin Proc. 1986; 61(8):671-5.

6. Al-Watban FAH, Zhang Z. Dosimetry-related wound healing response in the rat model following helium neon laser LLLT. Laser Ther. 1994; 6(2):119-124.

7. Limeira Jr. FA. Avaliação do reparo ósseo com o uso de osso anorgânico e membrana reabsorvível após irradiação com laser diodo 830nm [dissertation]. Salvador: Universidade Federal da Bahia; 2001. 177p.

8. Pinheiro ALB, Oliveira MG, Martins PPM, Ramalho LMP, Oliveira MAM, Silva Jr. AN, Nicolau RA. Biomodulatory effects of LLLT on bone regeneration. Laser Ther. 2001; 13:73-9.

9. Nicola RA, Jorgetti V, Rigau J, Pacheco MT, dos Reis LM, Zângaro RA. Effect of low-power GaAIAs laser $(660 \mathrm{~nm})$ on bone structure and cell activity: an experimental animal study. Lasers Med Sci. 2003; 18(2):89-94.

10. Weber JBB, Pinheiro ALB, Oliveira MG, Oliveira FAM, Ramalho LMP. Laser therapy improves healing of bone defects submitted to autologous bone graft. Photomed Laser Surg. 2006; 24(1): 38-44.

11. Gerbi ME, Pinheiro AL, Marzola C, Limeira Jr. FdeA, Ramalho LM, Ponzi EA, Soares AO, Carvalho LC, Lima HV, Gonçalves, TO. Assessment of bone repair associated with the use of organic bovine bone and membrane irradiated at $830 \mathrm{~nm}$. Photomed Laser Surg. 2005; 23:382-8.

12. Saito S, Shimizu N. Stimulatory effects of low-power laser irradiation on bone regeneration in midpalatal suture during expansion in rat. Am J Orthod Dentofacial Orthop. 1997; 111:525-32.

13. Takeda Y. Irradiation effect of low-energy laser on alveolar bone after tooth extraction: experimental study in rats. Int J Oral Maxillofac Surg. 1988; 17:38891.

14. Silva Jr. AN. Avaliação do efeito do laser diodo (GaAIAs) infravermelho de 830nm na biomodulação da cicatrização óssea [thesis]. Porto Alegre: Pontifícia Universidade Católica do Rio Grande do Sul; 2000. 116p.

15. Ozawa Y, Shimizu N, Kariya G, Abiko Y. Low-energy laser irradiation stimulates bone nodule formation at early stages of cell culture in rat calvarial cells. Bone. 1998; 22:347-54. 